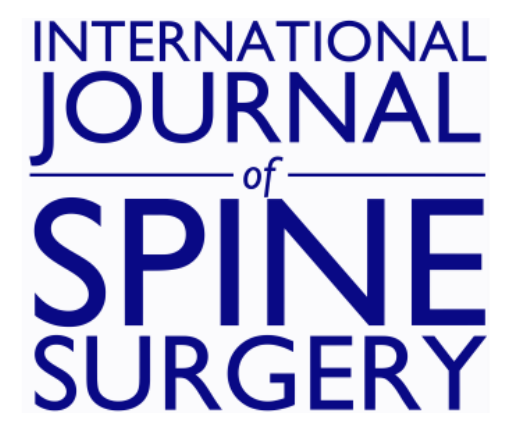

\title{
Fellowship and Practice Composition Affect Surgical Decision Making in Patients with Adult Degenerative Scoliosis: Spinal Deformity versus Degenerative Spinal Surgeons
}

Themistocles Protopsaltis, Ashish Patel, Andrew Yoo, Baron Lonner and John A. Bendo

Int J Spine Surg 2015, 9 ()

doi: https://doi.org/10.14444/2021

http://ijssurgery.com/content/9/21

This information is current as of April 26, 2023.

Email Alerts Receive free email-alerts when new articles cite this article. Sign up at:

http://ijssurgery.com/alerts

The International Journal of Sphine Surgerbittp://ijssurgery.com/ by guest on April 26, 2 2397 Waterbury Circle, Suite 1,

Aurora, IL 60504, Phone: +1-630-375-1432

(C) 2015 ISASS. All Rights Reserved. 


\section{Fellowship and Practice Composition Affect Surgical Decision Making in Patients with Adult Degenerative Scoliosis: Spinal Deformity versus Degenerative Spinal Surgeons}

Themistocles Protopsaltis, $M D^{1}$, Ashish Patel, $M D^{2}$, Andrew Yoo, BA1, Baron Lonner, MD1, John A. Bendo, $M D^{1}$

${ }_{1} N Y U$ Hospital for Joint Diseases, New York, NY, USA ${ }^{2} S U N Y$ Downstate Medical Center, Brooklyn, NY, USA

\section{Background}

For the Adult Degenerative Scoliosis (ADS) patient with radiculopathy, there is no clear data in the literature to guide the spine surgeon's decision making in choosing between limited decompression alone, short segment fusion, or longer arthrodesis of the deformity. This study investigates the differences in operative planning, for patients with ADS and radiculopathy, between two groups of spine surgeons based on fellowship experience and practice composition.

\section{Methods}

Six Degenerative Spine surgeons (Group 1) and 6 Spinal Deformity surgeons (Group 2) were shown 7 cases of patients with ADS and radiculopathy. Surgeons completed a questionnaire detailing their planned operative intervention including the number of fusion levels, if any, approach, choice of bone graft, and interbody device. Pearson Correlation was used to investigate the association between fellowship training, practice composition, number of levels fused, and other variables. Intraclass correlation (ICC) analysis was used to investigate the internal consistency among the groups.

\section{Results}

There was a direct correlation between fellowship deformity experience and practice composition $(\mathrm{r}=0.75$, $\mathrm{p}<0.01)$, and between deformity practice composition and the number of planned fusion levels $(\mathrm{r}=0.90, \mathrm{p}<0.001)$. Group 1 surgeons fused a mean 3.7 vertebral levels (range 0-6.7), while Group 2 surgeons fused a mean 10.8 levels (range 4-16.5). Group 2 surgeons fused a significantly greater number of levels for each case than degenerative surgeons on paired student t-test ( $\mathrm{p}=0.002)$. Group 1 surgeons chose decompression alone more commonly than deformity surgeons $(\mathrm{p}<0.05)$. Group 2 surgeons had significantly higher group consistency by ICC analysis $(\mathrm{p}=0.004)$.

\section{Conclusions}

Fellowship and practice composition influence the physician's surgical planning in ADS. There is a lack of standardized treatment paradigms for the management of radiculopathy in patients with ADS.

KEYWORDS: ADULT DEGENERATIVE SCOLIOSIS, PREOPERATIVE PLANNING, SPINE

VOLUME 9 ARTICLE 21 DOI: 10.14444/2021

\section{Introduction}

With the aging of our population and the rising functional expectations of our elderly patients, optimizing the quality of life for patients with adult spinal deformity is an issue of increasing concern. Glassman et al. demonstrated that increasing sagittal imbalance correlated with significant disability by validated out- come measures. ${ }^{1}$ Lafage et al. showed that the sagittal vertical axis (SVA) and pelvic tilt (PT) were the two most important radiographic parameters correlating with health related quality of life (HRQOL) outcomes. $^{2}$

Authors contributing to the adult spinal deformity literature have identified the patients most likely to 
benefit from major scoliosis correction, such as those with major sagittal imbalance and those who have severe preoperative disability. ${ }^{1-3}$ However, Schwab et al. showed that the same type of patients that are most likely to improve with scoliosis correction are also more likely to suffer major complications. ${ }^{3}$ In a systematic review of adult spinal deformity surgery, the perioperative complication rate was found to be $40 \%$ and the rate of pseudoarthrosis was $13 \% .{ }^{4}$ By contrast, Cho and colleagues showed that patients with degenerative scoliosis that underwent shorter segment fusion operations had better outcomes than those patients who underwent longer fusions beyond the end vertebra of their major curves. ${ }^{5}$

The patient with adult degenerative scoliosis (ADS) and intractable leg pain presents a management challenge for the spine surgeon. Smith and colleagues showed that such patients fared better when treated with surgery rather than nonoperative treatments. ${ }^{6}$ However, the surgical group was not sub-analyzed according to the magnitude of the surgical intervention. ${ }^{6}$ For the adult scoliosis patient with radiculopathy, there is no clear data in the literature to guide the spine surgeon's decision-making in choosing between limited decompression alone, short segment fusion, and/or longer arthrodesis of the deformity.

In our study, we sought to explore the philosophical differences and preoperative planning biases between two groups of surgeons: 1) degenerative spinal surgeons and 2) spinal deformity surgeons. The purpose of this study was to document and analyze the differences in operative strategies among surgeons who differ in their fellowship training and practice compositions when presented with the same set of ADS patient cases that include histories, physical exam findings, and complete radiologic studies. The patient cases were limited to patients with ADS and radiculopathy because there is no consensus in the literature to support either long fusion constructs or limited procedures in such cases.

\section{Materials and Methods}

This study was approved by our Institutional Review Board (IRB). Twelve experienced, fellowship-trained spine surgeons were shown 7 cases of symptomatic
ADS patients with radiculopathy. Seven of the 12 spine surgeons attended fellowship in New York City, while only 2 surgeons completed fellowships outside the United States. All 12 currently hold faculty positions at one institution in New York City (Table 1).

The spine surgeons were divided into two groups depending on the percentage of spinal deformity in their practice. Group 1 (Degenerative spinal surgeons) consisted of surgeons who do mostly degenerative spine surgeries with practices comprised of less than 50\% spinal deformity. Group 2 (Spinal deformity surgeons) consisted of surgeons who had practice compositions with greater than or equal to $50 \%$ spinal deformity.

\section{Case Selection}

The inclusion criteria of the surgical cases presented to the surgeons were as follows: lumbar curve be-

\begin{tabular}{|c|c|c|c|c|}
\hline Surgeon & $\begin{array}{l}\text { Years in } \\
\text { Practice }\end{array}$ & $\begin{array}{r}\text { Fellowship } \\
\text { Location }\end{array}$ & $\begin{array}{r}\text { Fellowship \% } \\
\text { Deformity }\end{array}$ & $\begin{array}{r}\text { Practice \% } \\
\text { Deformity }\end{array}$ \\
\hline $\begin{array}{l}\text { Degenerative } \\
1\end{array}$ & 10 & Plano, Texas & 10 & 15 \\
\hline $\begin{array}{l}\text { Degenerative } \\
2\end{array}$ & 6 & $\begin{array}{r}\text { New York, } \\
\text { NY }\end{array}$ & 20 & 20 \\
\hline $\begin{array}{l}\text { Degenerative } \\
3\end{array}$ & 13 & $\begin{array}{r}\text { New York, } \\
\text { NY }\end{array}$ & 25 & 5 \\
\hline $\begin{array}{l}\text { Degenerative } \\
4\end{array}$ & 15 & $\begin{array}{r}\text { New York, } \\
\text { NY }\end{array}$ & 50 & 20 \\
\hline $\begin{array}{l}\text { Degenerative } \\
5\end{array}$ & 12 & $\begin{array}{r}\text { Baltimore, } \\
\text { MD }\end{array}$ & 20 & 20 \\
\hline $\begin{array}{l}\text { Degenerative } \\
6\end{array}$ & 16 & $\begin{array}{r}\text { Philadelphia, } \\
\text { PA }\end{array}$ & 20 & 10 \\
\hline Deformity 1 & 25 & $\begin{array}{r}\text { Toronto, } \\
\text { Canada }\end{array}$ & 80 & 80 \\
\hline Deformity 2 & 11 & $\begin{array}{r}\text { New York, } \\
\text { NY }\end{array}$ & 70 & 50 \\
\hline Deformity 3 & 14 & $\begin{array}{r}\text { New York, } \\
\text { NY }\end{array}$ & 50 & 90 \\
\hline Deformity 4 & 15 & $\begin{array}{r}\text { New York, } \\
\text { NY }\end{array}$ & 50 & 70 \\
\hline Deformity 5 & 35 & $\begin{array}{l}\text { Marseille, } \\
\text { France }\end{array}$ & 75 & 75 \\
\hline Deformity 6 & 4 & $\begin{array}{r}\text { New York, } \\
\text { NY }\end{array}$ & 35 & 65 \\
\hline
\end{tabular}

Downloaded from http://ijssurgery.com/ by guest on April 26, 2023 
tween $25^{\circ}-40^{\circ}$, Thoracic Kyphosis (T2-T12) between $20^{\circ}-50^{\circ}$, Lumbar Lordosis (L1-S1) between $30^{\circ}-65^{\circ}$, and Sagittal Vertical Axis (SVA: C7 Plumbline to posterior-superior S1) between 0-80mm. Patients with spondylolithesis or lateral listhesis $>$ Grade 1, cauda equina syndrome, or prior thoracic or lumbar instrumentation and fusion were excluded. Each case was presented with a brief history, physical exam findings, PA and lateral radiographs, and MRI and CT scans. The Surgimap Spine program (Nemaris Inc., New York, NY) was utilized to measure and display radiographic parameters such as the Cobb angles, lumbar lordosis, pelvic parameters, and SVA. Table 2 outlines the Cobb angles, SVA, pelvic parameters, and chief complaint presented by each case. An example of the type of case displayed to the surgeons is shown in Figure 1, Figure 2, Figure 3, Figure 4, \& Figure 5 (corresponding to Case 2).

\section{Surgeon and Case Data}

The surgeons completed a questionnaire detailing their fellowship and practice, deformity experience, and their planned operative intervention including the number of fusion levels. Besides specifying the levels to be fused (if any) and the levels to be decompressed, the surgeons also specified the type of approach (anterior vs. posterior), the use (if any) of an interbody spacer, the type of bone graft (if any), and the extent of the decompression. Data collected from the surgeons for each case is summarized in Table 3.

\begin{tabular}{|c|c|c|c|c|c|c|c|c|}
\hline \multirow[b]{2}{*}{ Case } & \multicolumn{3}{|c|}{$\begin{array}{r}\text { Magnitude of } \\
\text { Curve }\left({ }^{\circ}\right)\end{array}$} & \multirow[b]{2}{*}{$\begin{array}{r}\text { SVA }^{4} \\
(\mathrm{~mm})\end{array}$} & \multicolumn{3}{|c|}{$\begin{array}{r}\text { Pelvic Parame- } \\
\text { ters }\left({ }^{\circ}\right)\end{array}$} & \multirow[b]{2}{*}{ Chief complaint } \\
\hline & $\mathrm{T}^{1}$ & $\mathrm{TL}^{2}$ & $\mathrm{~L}^{3}$ & & $\mathrm{PI}^{5}$ & $\mathrm{PT}^{6}$ & $\mathrm{SS}^{7}$ & \\
\hline 1 & 36 & 35 & $\mathrm{x}$ & 52 & 71 & 33 & 40 & $8 / 10$ leg pain \\
\hline 2 & $\mathrm{x}$ & 25 & 33 & 42 & 45 & 12 & 33 & $\begin{array}{r}9 / 10 \text { leg pain ( } \mathrm{R} \\
>\mathrm{L})\end{array}$ \\
\hline 3 & $\mathrm{x}$ & 24 & $\mathrm{x}$ & 77 & 59 & 23 & 38 & $\begin{array}{r}9 / 10 \text { leg pain } \\
(\mathrm{B} / \mathrm{L})\end{array}$ \\
\hline 4 & $\mathrm{x}$ & 23 & 33 & 52 & 61 & 44 & 17 & 6/10 leg pain \\
\hline 5 & $\mathrm{x}$ & 17 & 26 & 62 & 49 & 26 & 23 & $6 / 10$ leg pain \\
\hline 6 & $\mathrm{x}$ & 32 & $\mathrm{x}$ & 59 & 47 & 32 & 15 & 8/10 leg pain \\
\hline 7 & 76 & 62 & $\mathrm{x}$ & 12 & 61 & 22 & 39 & $\begin{array}{r}10 / 10 \text { leg pain } \\
(\mathrm{R})\end{array}$ \\
\hline
\end{tabular}

\section{Statistical Analysis}

The mean number of levels fused was compared between the groups with the Paired Student's t-test. Surgeon responses with regard to specific parameters such as the type of bone graft, the selection of approach, the use of an interbody cage, and the decision to choose decompression alone without fusion were quantified for each group and compared with the Paired Student's t-test. Pearson Correlation was used to investigate the association between fellowship training, practice composition, number of fusion levels, and the other variables (e.g. presence of

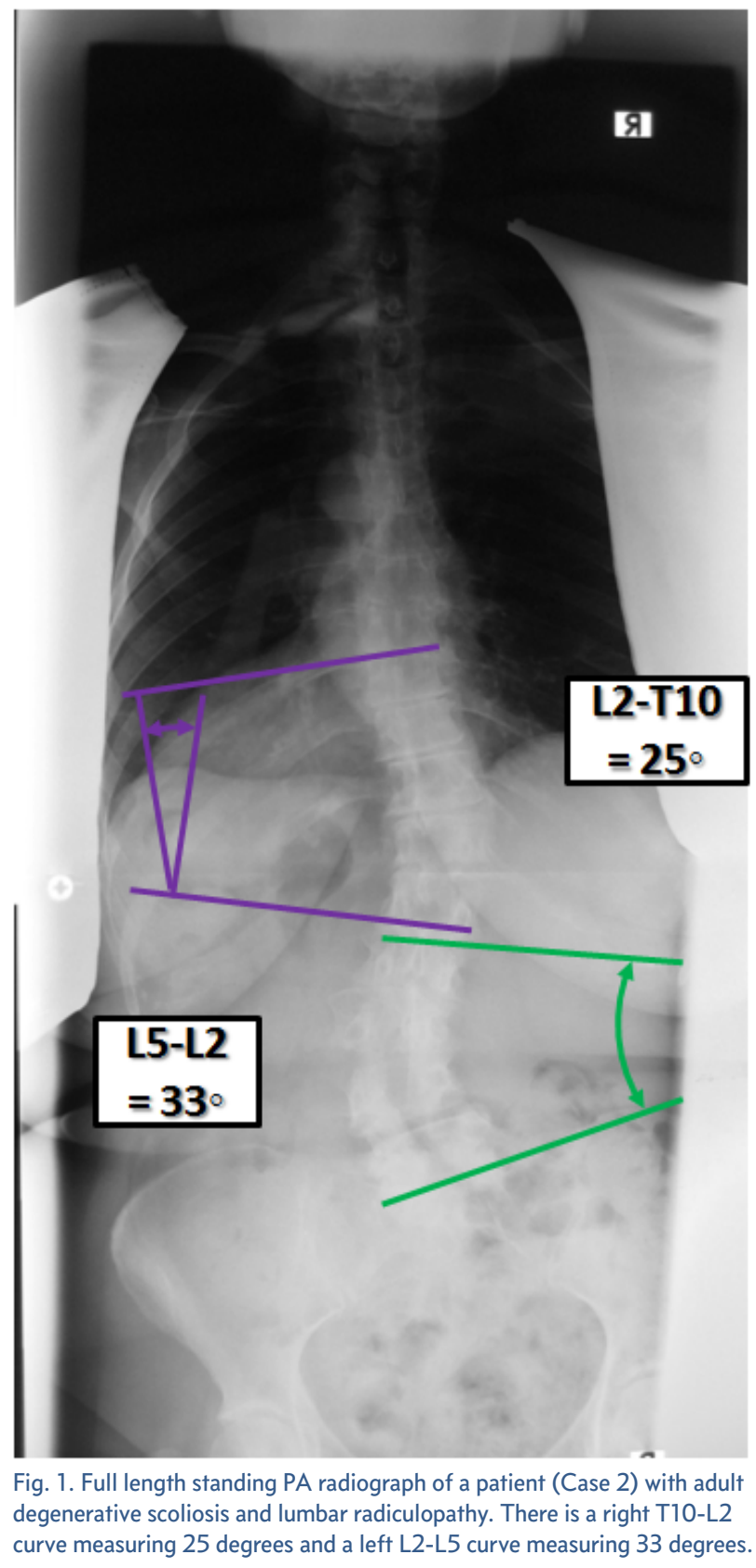

Downloaded from http://ijssurgery.com/ by guest on April 26, 2023 
spondylolisthesis, selection of approach, interbody spacer, bone graft, SVA, Cobb angle, lumbar lordosis). Intraclass correlation (ICC) analysis was used to investigate the internal consistency among the Group 1 and Group 2 surgeons.

\section{Results}

Fellowship and Practice

Degenerative Spinal surgeons (Group 1) on average were exposed to $24 \%$ deformity cases in their fellowships (range 10\%-50\%) while Spinal Deformity surgeons (Group 2) had a mean of 60\% (range 35\%-80\%)

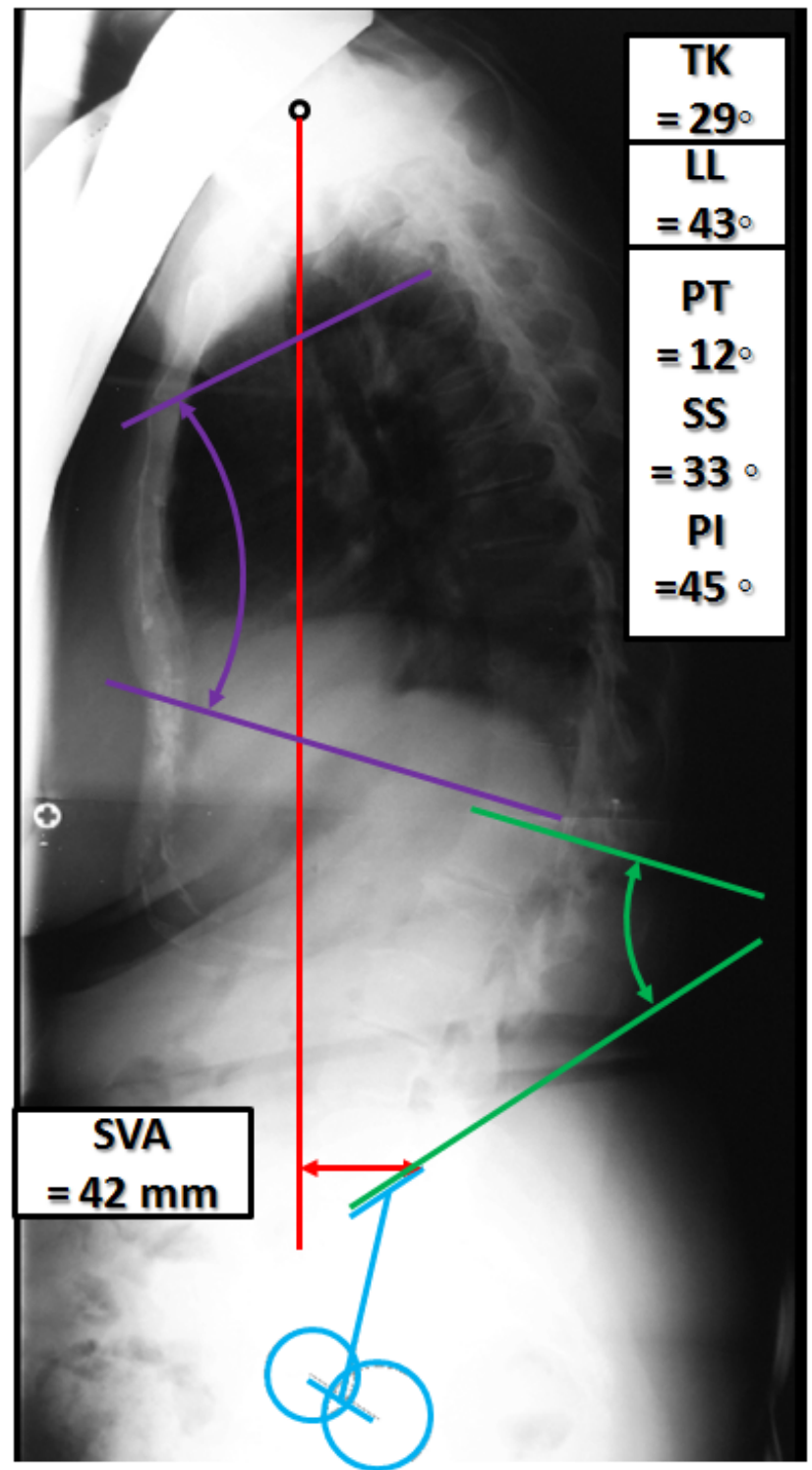

Fig. 2. Full length standing lateral radiograph of the patient (Case 2). The SVA measures $4.2 \mathrm{~cm}$, the pelvic incidence is 45 degrees, the pelvic tilt is 12 degrees and sacral slope is 33 degrees. Lumbar lordosis measures 43 degrees. Thoracic kyphosis measures 29 degrees. deformity experience. The mean deformity pathology in their practice was $15 \%$ (range 5\%-20\%) for Group 1 surgeons and $72 \%$ (range 50\%-90\%) for Group 2 sur-

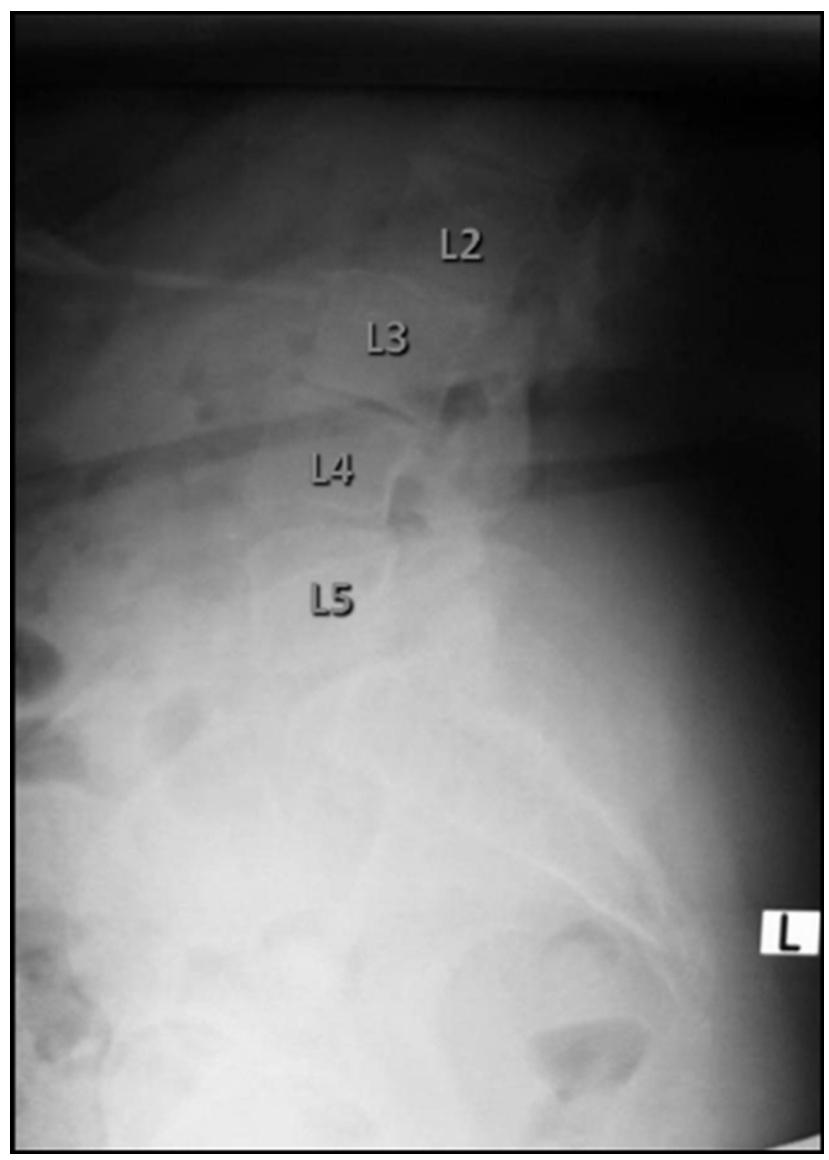

Fig. 3. Lateral radiograph of the lumbar spine (Case 2) demonstrates a grade 1 spondylolisthesis at L4-5 and grade 1 retrolisthesis at L3-4 and L2-3.

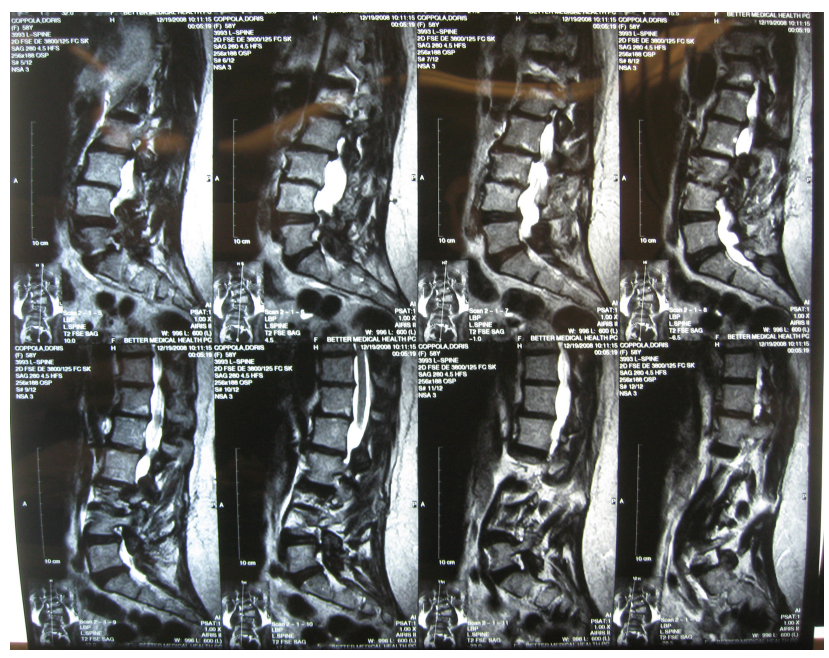

Fig. 4. Sagittal T2 MRI images of the patient (Case 2) with slices going from the left to the right of the patient. They are notable for prior L3-4 and L4-5 laminectomies. There is central stenosis at L1-2 and L2-3 and foramenal stenosis on the left at L1-2 and L2-3. 
geons (Table 1). Correlation between fellowship and practice spinal deformity composition was $r=0.75$, $\mathrm{p}<0.01$ (Figure 6).

\section{Fusion Levels}

The analysis of surgical planning demonstrated that Group 1 surgeons fused a mean 3.7 vertebral levels (range 0-6.7 levels) per case while Group 2 surgeons fused a mean 10.8 vertebral levels (range 4-16.5 levels) (Table 4). Group 2 surgeons fused a significantly greater number of levels for each case than Group 1 surgeons on Paired student t-test $(\mathrm{p}=0.002)$.

The mean number of levels fused for each case is depicted in Figure 7. Pearson correlation between the percentage of the surgeons' practice comprising spinal deformity and number of fusion levels was $\mathrm{r}=0.90(\mathrm{p}<0.001)$ (Figure 8$)$.

ICC analysis for the agreement among Group 2 surgeons for the number of levels fused per case was $\mathrm{r}=0.327$, (95\% Confidence Interval: 0.07-0.76, $\mathrm{p}=0.004)$. ICC for Group 1 surgeons was $\mathrm{r}=0.01(95 \%$ Confidence Interval: $-0.16-0.18, \mathrm{p}=0.842$ ).

\section{Selection of Approach and Other Variables}

There was no significant agreement within either group by intraclass correlation as to the selection of the type of bone graft, the use of interbody spacer, the extent of the decompression, or the selection of

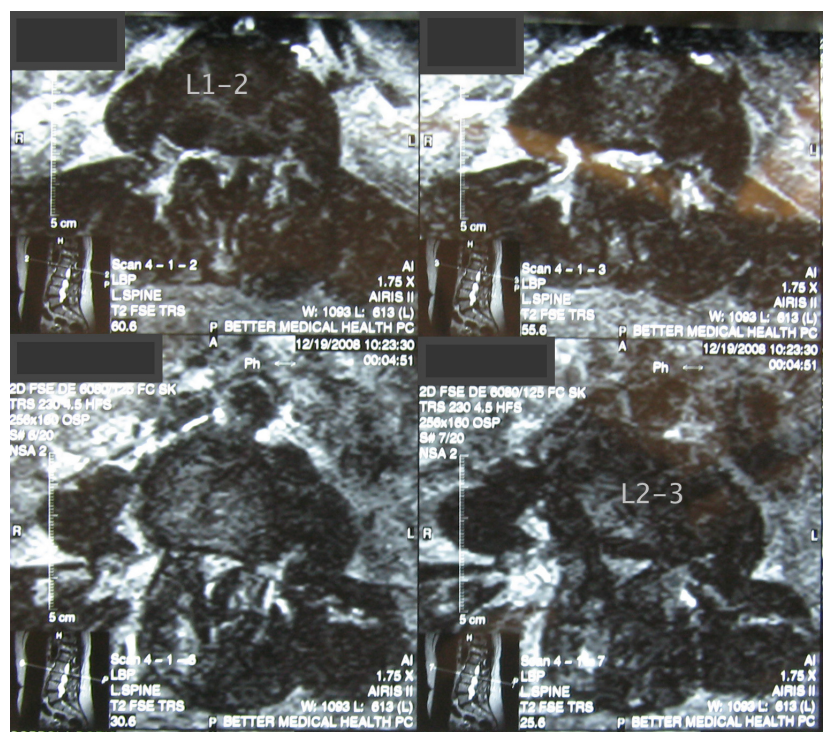

Fig. 5. Axial T2 MRI images showing central and lateral recess stenosis at L1-2 and L2-3 (Case 2). the approach. The presence of spondylolisthesis did not correlate with the selection of any particular approach (anterior/posterior versus all posterior), with

Table 3

\begin{tabular}{|c|c|c|}
\hline \multirow{3}{*}{ Procedure } & 1 & Posterior Decompression Alone \\
\hline & 2 & $\begin{array}{r}\text { Posterior Decompression and Fusion - No Instru- } \\
\text { mentation }\end{array}$ \\
\hline & 3 & Fusion with Instrumentation +/- Decompression \\
\hline \multirow{2}{*}{ Approach } & 1 & Posterior \\
\hline & 2 & Anterior/Posterior \\
\hline \multirow{7}{*}{ Interbody Spacer } & 1 & Metallic Cage \\
\hline & 2 & Polyetheretherketone (PEEK) Cage \\
\hline & 3 & Structural Allograft \\
\hline & 4 & Bone morphogenetic protein \\
\hline & 5 & Demineralized bone matrix \\
\hline & 6 & Bone Marrow Aspirate \\
\hline & 7 & Other \\
\hline \multirow{5}{*}{$\begin{array}{l}\text { Preferred Bone } \\
\text { Graft }\end{array}$} & 1 & Iliac crest bone graft \\
\hline & 2 & Bone morphogenetic protein \\
\hline & 3 & Local Autograft \\
\hline & 4 & Cancellous Allograft \\
\hline & 5 & Other \\
\hline \multirow{3}{*}{ Decompression } & 1 & Laminotomy \\
\hline & 2 & Laminectomy \\
\hline & 3 & Foramenotomy \\
\hline
\end{tabular}

Surgical planning data collected from each surgeon for each of the seven cases.

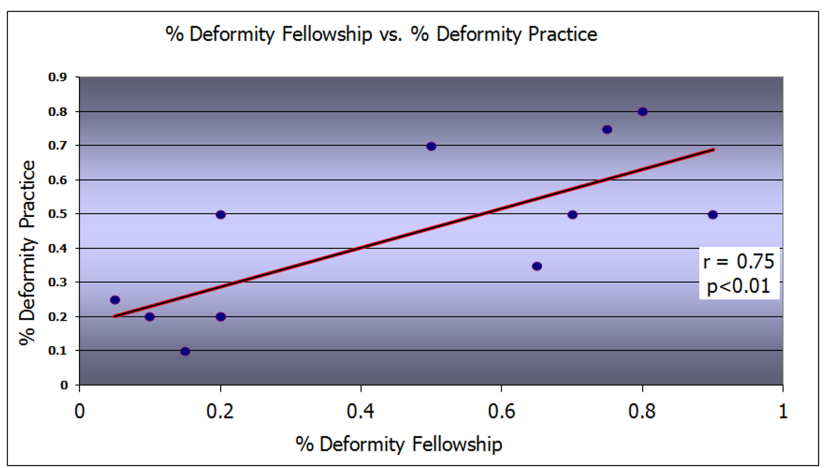

Fig. 6. Graphic depiction of the correlation between the percentage of spinal deformity in a surgeon's spine fellowship and the percentage of spine deformity in a surgeon's practice. There was a direct correlation with $\mathrm{R}=$ $0.75, p=0.01$ 
the choice to utilize an interbody spacer, or with the decision to fuse levels with spondylolistheses. A comparison of the responses of the two surgeon groups are summarized in Table 4. The selection of each parameter was quantified for each group as a percentage of the total possible responses by the 6 surgeons in each group for the 7 cases. The Group 1 surgeons planned decompression procedures alone without fusion more commonly than the Group 2 surgeons ( $37.1 \%$ vs. $11.9 \%$, respectively), a difference that was statistically significant $(\mathrm{p}<0.05)$. The Group 2 surgeons planned to utilize local autograft in $88 \%$ of their responses, compared to $60 \%$ of the responses for Group 1 surgeons $(\mathrm{p}<0.05)$.

\section{Discussion}

The surgical management of patients with ADS and radiculopathy presents a challenge for the spine surgeon in determining the optimal operative strategy. The adult spinal deformity literature has identified the patients most likely to benefit from major deformity correction, namely those with major sagittal imbalance and those with severe preoperative disabili-

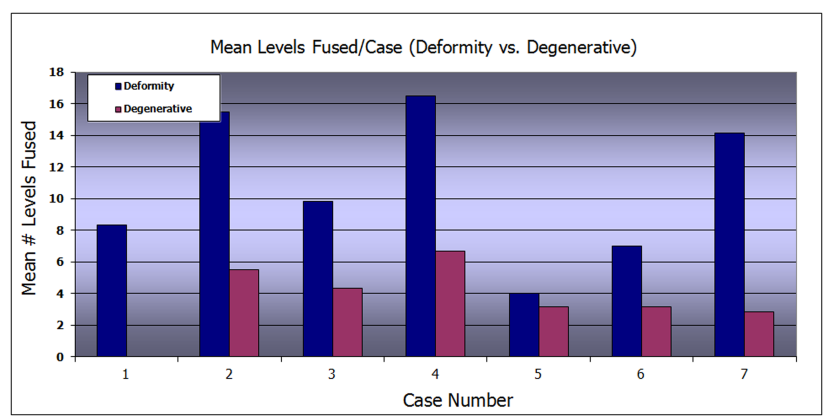

Fig. 7. Mean number of levels fused in each of the seven cases for each of the two groups of surgeons.

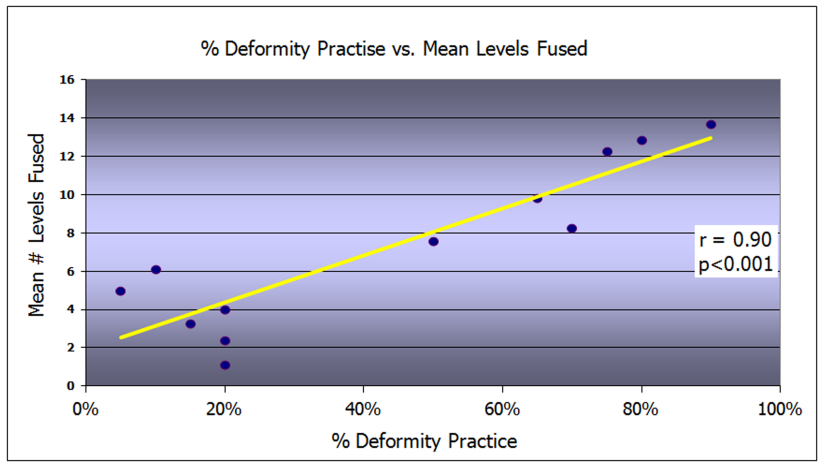

Fig. 8. Graphic depiction of the correlation between the percentage of deformity within a surgeon's practice and the mean number of levels fused for each case. There was a direct correlation with $R=0.84, p=0.001$. ty ${ }^{1-3}$ However, there may be situations in which more limited procedures, such as decompressions alone or short segment fusions may be successful in treating intractable leg pain in a patient with concurrent spinal deformity. ${ }^{7}$ There is little published in the literature to guide surgical management in the patient with ADS and intractable leg pain. This decision depends on individual patient factors and surgeon preferences. The purpose of this investigation was to determine the factors that might influence surgeon decision-making in the selection of operative strategies for the patient with lumbar radiculopathy and concurrent adult degenerative deformity.

Similar surgeon planning investigations have been undertaken in the study of adolescent idiopathic scoliosis (AIS) ${ }^{8-10}$ Aubin et al. conducted such a study in which 6 spine surgeons were shown 5 distinct cases of AIS and they were asked to plan surgical strategies for correction of the deformities. ${ }^{8}$ There was no agreement among the surgeons as to the choice of levels, the type of implants used at each level, i.e. hooks or screws, or the type of reduction maneuver to employ. ${ }^{8}$ In a follow up study by the same group, 32 surgeons from the Spinal Deformity Study Group were asked to detail their surgical plan for the correction of 5 standardized cases of AIS. ${ }^{9}$ There was poor intraobserver and interobserver agreement for the selection of fusion levels and fusion constructs. Lenke et al. showed good agreement among 28 surgeons in classifying 7 AIS cases, however, there was large variability in the selection of fusion levels and operative approach. ${ }^{10}$

Findings from this investigation demonstrate the association between spinal deformity experience during fellowship training and practice composition. In the setting of patients with ADS and radiculopathy, fellowship and practice composition have a significant influence on the spine surgeon's surgical planning. Our study explored philosophical differences among two groups of spine surgeons: Degenerative Spinal surgeons (Group 1) and Spinal Deformity surgeons (Group 2). We restricted our case presentations to patients with radiculopathy and adult degenerative scoliosis because we believe this represents a gray zone where there is no clear evidence in the literature to support long fusion constructs or limited 
procedures. The adult spinal deformity literature has established the benefits of deformity correction in patients with major sagittal imbalance. ${ }^{1-3}$ In our study, the Group 2 surgeons had significantly higher group consistency and planned a greater number of fusion levels on average than the Group 1 surgeons. This likely represents a philosophical predilection on the part of spinal deformity surgeons (Group 2) who are less likely to recommend a limited decompression alone for the treatment of patients with concurrent spinal deformity. Indeed, the degenerative spinal surgeons (Group 1) planned simple decompression procedures without fusion $37.1 \%$ of the time versus $11.9 \%$ for the Group 2 surgeons, a difference that was statistically significant $(\mathrm{p}<0.05)$. Further, the Group 1 surgeons chose to use local autograft in $60 \%$ of their responses compared to $88 \%$ for the Group 2 surgeons $(\mathrm{p}<0.05)$. This difference can be explained by the fact that Group 1 surgeons were more likely to recommend decompressions without fusions and they tended to use BMP without local autograft in a subset of their responses (as in the choice of an anterior/ posterior fusion using BMP in an interbody cage and percutaneous pedicle screws). In fact, Group 1 surgeons selected BMP in $20 \%$ of responses compared with $11.9 \%$ for the deformity surgeons, a difference that was not statistically significant.

Conversely, there was no agreement within either group by intraclass correlation as to the type of approach, the type bone graft, or the use of interbody spacers. There are myriad options for implants and surgical procedures in spine surgery and it is unlikely for there to exist any great degree of technique standardization among modern-day spine surgeons. Case parameters such as the presence of spondylolisthesis, the magnitude of the Cobb angle, and the degree of sagittal imbalance did not affect agreement among the groups with regard to approach or fusion levels (though none of the cases had SVA $>8.0 \mathrm{~cm}$ ). While there are studies that support decompression and fusion in the presence of spondylolisthesis, ${ }^{11}$ the lack of a correlation in this study is likely due to our small sample size of surgeons and the fact that many of the surgeons, particularly the Group 2 surgeons, tended to plan for a fusion in most of the cases due to other factors such as scoliotic deformity. Overall, this study demonstrates that there is a lack of standardized treatment paradigms for the management of radiculopathy in patients with spinal deformity.

The limitations of the study are the small sample size of surgeons and that, by design, this is a theoretical investigation. The surgeons based their decisions on slide presentations with limited information including short descriptions of the patients' history, pertinent physical exam findings, full length standing radiographs, MRIs, and CT scans. In praxis, surgical planning depends on many factors including a detailed patient history, medical comorbidities, and a complete physical exam, in addition to radiologic findings. In reality, the operative plan is devised with the input and agreement of the patient, tailored for each particular combination of patient characteristics, including not only the objective radiographic data but also subjective factors. Moreover an intraobserver analysis was not performed in this study. However, given the wide variability by case within each group and the dynamic nature of the modern spine surgeon's surgical experience, there was not likely to be a high degree of intraobserver agreement. Robitaille et al. showed very poor intraobserver relia-

Table 4.

\begin{tabular}{|c|c|c|c|c|c|c|c|c|c|c|c|c|c|}
\hline \multirow[b]{2}{*}{$\begin{array}{l}\text { Surgeon } \\
\text { Group }\end{array}$} & \multirow{2}{*}{$\begin{array}{r}\text { Mean } \\
\text { Levels } \\
\text { Fused }\end{array}$} & \multirow{2}{*}{$\begin{array}{r}\text { Posterior } \\
\text { Approach } \\
(\%)\end{array}$} & \multirow{2}{*}{$\begin{array}{r}\text { Anterior/ } \\
\text { Posterior } \\
\text { Approach } \\
(\%)\end{array}$} & \multirow[b]{2}{*}{$\begin{array}{r}\text { Decompression } \\
\text { Alone (\%) }\end{array}$} & \multicolumn{4}{|c|}{ Interbody Material } & \multicolumn{5}{|c|}{ Preferred Bone Graft } \\
\hline & & & & & $\begin{array}{l}\text { Structural } \\
\text { Allograft } \\
(\%)\end{array}$ & $\begin{array}{r}\text { Metallic } \\
\text { Cage } \\
(\%)\end{array}$ & $\begin{array}{r}\text { PEEK } 1 \\
(\%)\end{array}$ & $\begin{array}{r}\text { Other } \\
(\%)\end{array}$ & $\begin{array}{r}\mathrm{ICBG}^{2} \\
(\%)\end{array}$ & $\begin{array}{r}\text { Local } \\
\text { Autograft } \\
(\%)\end{array}$ & $\begin{array}{r}\text { Allograft } \\
(\%)\end{array}$ & $\begin{array}{r}\text { BMP3 } \\
(\%)\end{array}$ & $\begin{array}{r}\text { BM}^{4} \\
\text { Aspirate } \\
(\%)\end{array}$ \\
\hline $\begin{array}{l}\text { Group 1: } \\
\text { Degenerative }\end{array}$ & $3.7 \dagger$ & 72.5 & 27.5 & $37.5 \dagger$ & 10.0 & 15.0 & 12.5 & 2.5 & 12.2 & $60 \dagger$ & 12.5 & 20.0 & 0.0 \\
\hline $\begin{array}{l}\text { Group 2: } \\
\text { Deformity }\end{array}$ & $10.8 \dagger$ & 62.5 & 37.5 & $11.9 \dagger$ & 16.7 & 14.3 & 16.7 & 9.5 & 23.8 & $88.1 \dagger$ & 26.2 & 11.9 & 7.1 \\
\hline
\end{tabular}

Surgeon responses with respect to specific parameters are summarized for Group 1 and Group 2 surgeons. The selection of each parameter was quantified for each group as a percentage of the total possible responses for the 7 cases by the 6 surgeons in each group. The percentages were compared between the groups using the paired student's t-test, with significant differences noted $(\dagger)$. [1: polyetheretherketone; ${ }^{2}$ : iliac crest bone graft; ${ }^{3}$ : bone morphogenetic protein; ${ }^{4}$ : bone marrow]

Downloaded from http://ijssurgery.com/ by guest on April 26, 2023 
bility among 32 experienced spine surgeons planning surgeries for AIS cases. ${ }^{9}$ The poor intraobserver agreement in such surgical planning studies may be due to the constant evolution of surgical procedures in spine surgery where there is a continuous innovation of implants and techniques.

Our study underscores the need to establish well designed prospective clinical trials that can critically evaluate limited procedures versus long fusions in the treatment of adult spinal deformity patients with radiculopathy. Until such data is available, the consensus over treatment strategies for patients with ADS will remain at the level of expert opinion and philosophical surgeon bias.

\section{References}

1. Glassman SD, Bridwell K, Dimar JR, Horton W, Berven S, Schwab F. The impact of positive sagittal balance in adult spinal deformity. Spine (Phila Pa 1976) 2005;30:2024-9.

2. Lafage V, Schwab F, Patel A, Hawkinson N, Farcy JP. Pelvic tilt and truncal inclination: two key radiographic parameters in the setting of adults with spinal deformity. Spine (Phila Pa 1976) 2009;34:E599-606.

3. Schwab FJ, Lafage V, Farcy JP, Bridwell KH, Glassman S, Shainline MR. Predicting outcome and complications in the surgical treatment of adult scoliosis. Spine (Phila Pa 1976) 2008;33:2243-7.

4. Yadla S, Maltenfort MG, Ratliff JK, Harrop JS. Adult scoliosis surgery outcomes: a systematic review. Neurosurg Focus 2010;28:E3.

5. Cho KJ, Suk SI, Park SR, et al. Short fusion versus long fusion for degenerative lumbar scoliosis. Eur Spine J 2008;17:650-6.

6. Smith JS, Shaffrey CI, Berven S, et al. Operative versus nonoperative treatment of leg pain in adults with scoliosis: a retrospective review of a prospective multicenter database with two-year follow-up. Spine (Phila Pa 1976) 2009;34:1693-8.

7. Weidenbaum M. Considerations for focused surgical intervention in the presence of adult spinal deformity. Spine (Phila Pa 1976) 2006;31:S139-43.
8. Aubin CE, Labelle H, Ciolofan OC. Variability of spinal instrumentation configurations in adolescent idiopathic scoliosis. Eur Spine $J$ 2007;16:57-64.

9. Robitaille M, Aubin CE, Labelle H. Intra and interobserver variability of preoperative planning for surgical instrumentation in adolescent idiopathic scoliosis. Eur Spine J 2007;16:1604-14.

10. Lenke LG, Betz RR, Haher TR, et al. Multisurgeon assessment of surgical decision-making in adolescent idiopathic scoliosis: curve classification, operative approach, and fusion levels. Spine (Phila Pa 1976) 2001;26:2347-53.

11. Herkowitz HN, Kurz LT. Degenerative lumbar spondylolisthesis with spinal stenosis. A prospective study comparing decompression with decompression and intertransverse process arthrodesis. J Bone Joint Surg Am 1991;73:802-8.

\section{Disclosures}

Themistocles Protopsaltis is a consultant for Medicrea International and Biomet and his institution has received research support from Zimmer Spine. Baron Lonner has received research support from $\mathrm{AO}$ Spine and his institution has received research support from DePuy Spine; is a consultant for DePuy Spine, owns stock in Paradigm Spine and Spine Search, is a private investor in Paradigm Spine, is a scientific advisor to DePuy Spine, is on the Board of Directors for Spine Search, is on the speaker's bureau for DePuy Spine and K2M, and receives royalties from DePuy. The other authors declare no relevant disclosures.

\section{Corresponding Author}

John A. Bendo, MD, Hospital for Joint Diseases, NYU Langone Medical Center, 301 East 17th Street, Suite 400, New York, NY 10003, John.Bendo@nyumc.org.

Published 1 June 2015.

This manuscript is generously published free of charge by ISASS, the International Society for the Advancement of Spine Surgery. Copyright $\odot 2015$ ISASS. To see more or order reprints or permissions, see http://ijssurgery.com. 